\title{
DINÂMICA CLIMÁTICA DA REGIÃO SUL DO BRASIL ${ }^{1}$
}

\author{
Jonas Teixeira Nery ${ }^{2}$
}

\begin{abstract}
RESUMO
O objetivo deste trabalho foi analisar a precipitação pluvial em diferentes escalas. O período analisado foi de 1972 a 1997, para 127 séries de precipitação pluvial. Os dados foram cedidos pela Agência Nacional de Água (ANA). Diversos métodos estatísticos foram utilizados, tais como análise multivariada, componentes principais, bem como estatísticas mais simples: média, desvio padrão, coeficiente de variação, por exemplo. Também foram calculadas anomalias, para alguns anos, classificados de acordo com a ocorrência de El Niño e La Niña. Realizou-se análises subjetivas da Zona de Convergência do Atlântico Sul (ZCAS) e sua importância na precipitação pluvial da região sul do Brasil.
\end{abstract}

Palavras chave: ZCAS, EL Niño, precipitação pluvial, anomalias.

\section{CLIMATIC DYNAMIC OF BRAZILIAN SOUTHERN REGION}

\begin{abstract}
The purpose of this paper was analized a rainfall in different scales. Monthly rainfall data during 1972 to 1997 were taken in 127 rainfall series. The rainfall variability in the South region was analized through data obtained to Agencia Nacional de Água (ANA). South region presented significant rainfall variability of one for another year. This variability studied through the anomalies presented positive values in the years of 1983 , for example.
\end{abstract}

Keywords: ZCAS, EI Niño, rainfall, anomalies.

1 Palestra apresentada em mesa redonda do VI Simpósio Brasileiro de Climatologia, 13 a 16 de outubro de 2004, Aracaju, SE.

2 Professor Doutor, UNESP_Ourinhos, Geografia, Grupo GAIA/CNPq, jonas@ourinhos.unesp.br. 


\section{Introdução}

O Brasil, por ser um país de grande extensão territorial, possui diferenciados regimes de precipitação e temperatura. De norte a sul encontrase uma grande variedade de climas, com distintas características regionais. No Norte do país verifica-se um clima equatorial chuvoso, praticamente sem estação seca. No Nordeste a estação chuvosa, com baixos índices pluviométricos, restringe-se a poucos meses, caracterizando um clima semiárido. As regiões Sudeste e Centro-Oeste sofrem influência tanto de sistemas tropicais como de latitudes médias, com estação seca bem definida no inverno e estação chuvosa, no verão com chuvas convectivas. O sul do Brasil, devido à sua localização latitudinal, sofre mais influência dos sistemas de latitudes médias, onde os sistemas frontais são os principais causadores de chuvas durante o ano.

Com relação às temperaturas, observa-se nas regiões Norte e Nordeste temperaturas elevadas, com pouca variabilidade durante 0 ano, caracterizando o clima quente nestas regiões. Nas médias latitudes a variação da temperatura no decorrer do ano é muito importante na definição do clima. No período de inverno há maior penetração de massas de ar frio de altas latitudes, o que contribui para a predominância de baixas temperaturas (Quadro, 1994).

Estudar a região sul do Brasil e sua dinâmica é muito complexo e requer um olhar atento sobre os diferentes sistemas que atuam nessa região. Desde já deve ser ressaltado que muitas dinâmicas explicativas das chuvas intensas ou mesmo a falta de chuva, da amplitude térmica dessa região, têm suas gênesis distante dessa área do Brasil. Descrever as circulações que influenciam a área de estudo requer uma passagem sobre outras regiões fundamentais na explicação dos extremos climáticos, ao longo de anos ou décadas e mesmo a variabilidade sazonal, intrasazonais e interanual, da região sul brasileira.

Fenômenos tais como as entradas de massas polares ao longo dos anos, mais evidentes, já não chamam tanta a atenção dos pesquisadores. 0 que realmente cria polêmica são as previsões de chuvas ou frios provenientes do extremo sul do continente sul americano. Por outro lado a organização de sistemas convectivos a partir desses sistemas frontais são estudos recentes, comparativamente as gêneses das massas polares. Outros sistemas importantes são os Complexos Convectivos de Mesoescala (MCC), atuantes principalmente na primavera e verão, além das Zonas de Convergência do Atlântico Sul (ZCAS), também com atuação a partir de setembro/outubro estendendo-se até março/abril. Esses sistemas ocorrem principalmente sobre o Brasil central, com seu eixo estendendo de noroeste a sudeste, fundamentais na explicação das chuvas de verão, em grande parte da região Sul, dependendo do ano, pode até mesmo atingir toda essa região.

A organização desses sistemas, através das massas polares é importante para explicar as chuvas tanto na região sul quanto na sudeste, sendo, portanto, importante o monitoramento dessas dinâmicas para uma melhor previsão das precipitações pluviais que ocorrem ao longo das estações primavera/verão.

Outro evento que, apesar de ocorrer distante da área de estudo, influencia sobremaneira as chuvas da região sul do Brasil é o fenômeno EL Niño 
- Oscilação Sul (ENOS). Esse fenômeno que está vinculado ao aquecimento (resfriamento) da água do Oceano Pacífico Tropical, provocando eventos El Niño (La Niña), pode provocar chuvas intensas no sul do Brasil, conforme o ocorrido em 1982/83 e 1997/98. Essa teleconecção entre a atmosfera (Oscilação Sul) e o oceano Pacífico (El Niño ou La Niña), está sendo monitorada diuturnamente por satélites, bóias, navios, aviões, para se ter uma previsão mais precisa dos eventos, pois se sabe que os mesmos provocam alterações nas dinâmicas climáticas em todo o mundo. Na região Sul do Brasil o evento El Niño provoca chuvas acima da normal climatológica e, na ocorrência dos episódios La Niña, anomalias negativas da precipitação pluvial, nessa região.

A relação entre anomalias positivas de precipitação pluvial e a ocorrência do fenômenos El Niño - Oscilação Sul (ENOS) foi confirmada através de vários estudos. Ropelewski e Halpert (1987) e Kousky e Ropelewski (1989) afirmaram que esta relação se dá no período de novembro a fevereiro. Entretanto, durante o episódio ENOS 1982-83 a região Sul foi afetada com precipitação pluvial acima da normal durante o mês de julho. Rao e Hada (1994) encontraram significativas correlações entre as anomalias de precipitação e o Índice de Oscilação Sul (IOS) durante a primavera. Grimm (1992), analisando esta relação a partir de indicações das funções de Green de um modelo barotrópico baseado na equação da vorticidade, sugeriu relações diferenciadas entre eventos ENOS e a precipitação pluvial no Sul do Brasil, no inverno (anomalias positivas de precipitação pluvial) e verão (anomalias negativas de precipitação pluvial)

Outras dinâmicas são importantes para entender as variações de temperaturas, precipitações, dentre outros elementos meteorológicos, sob essas áreas de estudo. Por exemplo, a ciclogênesis no litoral catarinense que está associada ao gradiente térmico, bem como as depressões devido ao encontro das águas aquecidas da corrente oceânica do Brasil com as correntes frias das Malvinas, provocando um gradiente térmico, causador, muitas vezes, de intensificação de frentes frias que se deslocam sobre essa região. É também uma área de intensa atividade convectiva, produzindo ciclones extra tropicais e, particularmente, um possível furacão, com prejuízos econômicos importantes na região, no ano passado.

Desta forma, estudar a dinâmica climática da região sul do Brasil requer uma análise sobre esses eventos, além da questão da continentalidade, maritimidade, por exemplo, que são efeitos locais, gerando climas regionais dentro de cada área estudada.

A região Sul está localizada abaixo do Trópico de Capricórnio, em uma zona temperada. É influenciada pelo sistema de circulação perturbada de Sul, responsável pelas chuvas, principalmente no verão e pelo sistema de circulação perturbada de Oeste, que acarreta chuva intensa, por vezes granizo, com ventos com rajadas de 60 a $90 \mathrm{Km} / \mathrm{h}$.

Quanto ao regime térmico, o inverno é frio e o verão é quente. A temperatura média anual situa-se entre $14^{\circ}$ e $22^{\circ} \mathrm{C}$, em nos locais com altitudes acima de $1.100 \mathrm{~m}$, cai para aproximadamente $10^{\circ} \mathrm{C}$.

No verão, principalmente em janeiro, nos vales dos rios Paranapanema, Paraná, Ibicuí-Jacuí, a temperatura média é superior a $24^{\circ} \mathrm{C}$ e do rio Uruguai ultrapassa a $26^{\circ} \mathrm{C}$. A média das máximas mantém-se em torno de $24^{\circ}$ a $27^{\circ} \mathrm{C}$ nas superfícies mais elevadas do planalto e, nas áreas mais baixas, entre $30^{\circ}$ e $32^{\circ} \mathrm{C}$. 
No inverno, principalmente em julho, a temperatura média se mantém relativamente baixa, oscilando entre $10^{\circ}$ e $15^{\circ} \mathrm{C}$, com exceção dos vales dos rios Paranapanema e Paraná, além do litoral do Paraná e Santa Catarina, onde as médias são de aproximadamente $15^{\circ}$ a $18^{\circ} \mathrm{C}$. A média das máximas também é baixa, em torno de $20^{\circ}$ a $24^{\circ} \mathrm{C}$, nos grandes vales e no litoral e $16^{\circ}$ a $20^{\circ} \mathrm{C}$ no planalto. A média das mínimas varia de $6^{\circ}$ a $12^{\circ} \mathrm{C}$, sendo comum o termômetro atingir temperaturas próximas de $0^{\circ} \mathrm{C}$, ou mesmo alcançar índices negativos, acompanhados de geada e neve, quando da invasão das massas polares.

A pluviosidade média anual oscila entre 1.250 e $2.000 \mathrm{~mm}$, exceto no litoral do Paraná e oeste de Santa Catarina, onde os valores são superiores a $2.000 \mathrm{~mm}$ e no norte do Paraná e pequena área litorânea de Santa Catarina, com valores inferiores a $1.250 \mathrm{~mm}$. O máximo pluviométrico acontece no inverno e o mínimo no verão em quase toda a região.

O objetivo desse trabalho é dar um panorama geral sobre essas dinâmicas que influenciam a região Sul do Brasil, contribuindo, desta forma, para o debate da comunidade geográfica afeito ao estudo do clima, sobre a variabilidade climática dessa região que coube a mim, apresentar.

\section{Dinâmica da Zona de Convergência do Atlântico Sul (ZCAS)}

Convencionalmente definida como uma persistente faixa de nebulosidade orientada no sentido noroeste-sudeste, que se estende do sul da Amazônia ao Atlântico Sul-Central por alguns milhares de quilômetros, bem caracterizada nos meses de verão.

Estruturas semelhantes são encontradas no Pacífico Sul e Índico Sul, sendo que a Zona de Convergência do Índico Sul (ZCIS) não é tão marcante quanto as demais.

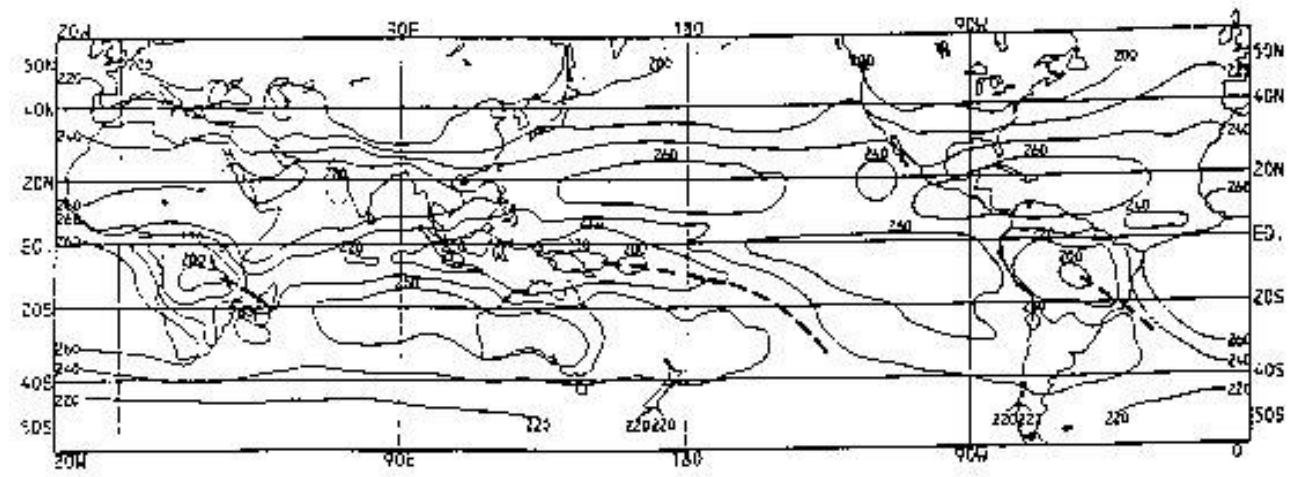

Figura 1. Campo médio de Radiação de Onda Longa Emergente, para o mês de janeiro (período base de 1974 a novembro de 1983). O intervalo de contorno é de $20 \mathrm{Wm}^{-2}$, com valores maiores que $280 \mathrm{Wm}^{-2}$, dados por linha pontilhada.

Fonte: Janowiak et al., 1985.

Estudos prévios mostram o importante papel dessas bandas de nebulosidade na transferência de calor, momento e umidade dos trópicos para as latitudes mais altas. 
Observações indicam evidente associação entre períodos de enchentes de verão na região sudeste e veranicos na região sul com a permanência da ZCAS por períodos prolongados sobre a região sudeste; por outro lado, períodos extremamente chuvosos no sul coincidem com veranicos na região sudeste, indicando a presença de ZCAS mais ao sul. Padrão de dipolo entre anomalias de precipitação pluvial nas regiões Sul e Sudeste devido à influência da ZCAS.

O estudo observacional feito por Kodama (1992) mostrou diversas características comuns entre a ZCAS, a Zona de Convergência do Pacífico Sul (ZCPS) e a Zona Frontal de Baiu, chamadas, de uma forma geral, de Zonas de Convergência Subtropical (ZCST),conforme a Figura1.

\section{Circulação durante o verão}

Níveis baixos: escoamento de norte-noroeste que começa junto à encosta leste dos Andes e se prolonga até a região sudeste do Brasil em forma de jato, sendo muito importante para o transporte de umidade da região amazônica para o Brasil Central e regiões Sul - Sudeste.

Níveis altos: circulação anticiclônica (alta da Bolívia) e um cavado quase-estacionário sobre o nordeste do Brasil.

Forte indício de confluência entre o ar da alta Subtropical do Atlântico Sul e o ar oriundo de latitudes mais altas; esta confluência deve estar acompanhada de convergência de umidade e nebulosidade; em níveis superiores, a configuração mais favorável corresponde a um cavado a leste dos Andes de maneira que a divergência em altitude seja incentivada; além disso, deve haver persistência de pelo menos quatro dias desta configuração, pois caso contrário a confluência pode ter sido gerada pela penetração de um sistema frontal; a ZCAS nem sempre apresenta estrutura típica de um sistema frontal ao analisar os gradientes de temperatura; porém o contraste de umidade em geral pode ser identificado, principalmente se for utilizada a temperatura potencial equivalente; as observações indicam que a ZCAS tende a se posicionar mais ao norte no início do verão, deslocando-se posteriormente para o sul podendo variar até $10-15^{\circ}$ de latitude; isto resulta em situações distintas para determinados locais, conforme a região de estacionalidade da ZCAS; análise dos mecanismos candidatos a importantes postos na formação e persistência da ZCAS: liberação de calor latente na América do Sul.

A dinâmica da ZCAS indica que o aquecimento localizado sobre o continente da América do Sul exerce papel fundamental para as zonas de confluência; em estudos numéricos prévios, a resposta estacionária de um modelo atmosférico a uma forçante simétrica e localizada de calor, com estado básico semelhante ao observado na América do Sul, sem topografia, indica a formação de um cavado na baixa troposfera orientado na direção da ZCAS e também a formação de um anticiclone em ar superior (neste caso, a advecção de vorticidade planetária tem papel importante na resposta assimétrica à forçante simétrica); uma vez estabelecido o cavado orientado, inicia-se a convecção organizada em forma de banda e a partir daí é possível que a convecção adquira um caráter quase-estacionário tendo em vista o mecanismo 
CISK; trata-se, portanto de um sistema em que há importante influência do acoplamento entre a escala convectiva (que fornece o aquecimento da atmosfera via liberação de calor latente) e a dinâmica que permite o abaixamento da pressão contribuindo para a manutenção e intensificação da convergência de massa e vapor de água que sustenta a própria conveç̧ão; a princípio, o estabelecimento de condições quase-estacionárias a partir de intensa liberação de calor latente é aparentemente contraditório no sentido que fenômenos altamente convectivos tendem a excitar modos atmosféricos de alta freqüência (ondas de gravidade); para esclarecer esta dúvida, uma análise do efeito da liberação de calor latente num modelo simplificado da atmosfera, baseado em equações de águas rasas linearizadas com relação a um estado básico em repouso com altura média constante, cuja parametrização da liberação de calor latente se dá pela inclusão de um termo de fonte de massa proporcional à divergência.

Quanto aos fatores remotos, Casarim e Kousky (1986) mostraram que a convecção na região centro-oeste do Pacífico, especificamente na ZCPS, implicava numa posterior intensificação da ZCAS, sugerindo um mecanismo de propagação do tipo oscilação de 30-60 dias. A simulação de uma onda estacionária associada ao padrão definido pela ZCPS/ZCAS, com um modelo de circulação geral da atmosfera (Kalnay et al., 1986), mostrou que a existência dessa onda estava vinculada à conveção na região tropical e nas próprias Zonas de Convergência.

Diversos podem ser os fatores locais, porém, o único consenso parece ser quanto ao papel da convecção na região Amazônica. Em um estudo observacional das Zonas de Convergência Sub-Tropicais, Kodama (1993) mostrou que essas zonas aparecem somente quando duas condições de grande escala são satisfeitas: (i) o escoamento de ar quente e úmido, em baixos níveis, em direção às altas latitudes; e (ii) um jato sub-tropical (JST) em altos níveis fluindo em latitudes subtropicais. O escoamento em baixos níveis intensifica a convergência de umidade enquanto, combinado com o JST, intensifica a frontogênese no campo da temperatura potencial equivalente, influindo na geração da instabilidade convectiva. O estabelecimento desse padrão de circulação está claramente associado à atividade convectiva na Amazônia e Brasil Central, que intensifica o JST em altos níveis, em um processo de conversão de energia cinética divergente em energia cinética rotacional (Hurrel e Vincent, 1991). Em baixos níveis a conveç̧ão também contribui na intensificação da Baixa na região do Chaco, que fortalece a convergência de ar úmido sobre a região.

Quanto ao efeito local dos Andes sobre a ZCAS, Figueroa et al., (1994) mostraram, por experimentos numéricos, que o posicionamento adequado desse sistema depende da inclusão da topografia nas simulações. Entretanto, um aspecto interessante (Figueroa et al., 1994; Gandu e Geisler, 1991; Kalnay et al., 1986) é que, simulações sem a inclusão da topografia, conseguem reproduzir um padrão de divergência (convergência) alongada em altos (baixos) níveis, com orientação semelhante à da ZCAS. Assim, embora os Andes não tenham um papel preponderante na gênese da ZCAS, aparentemente intensificam o escoamento em baixos níveis, auxiliando assim a 
alimentação da convergência com o ar úmido da região Amazônica.

As imagens a seguir apresentam o início e o final de uma ZCAS, ocorrida em janeiro de 1997.
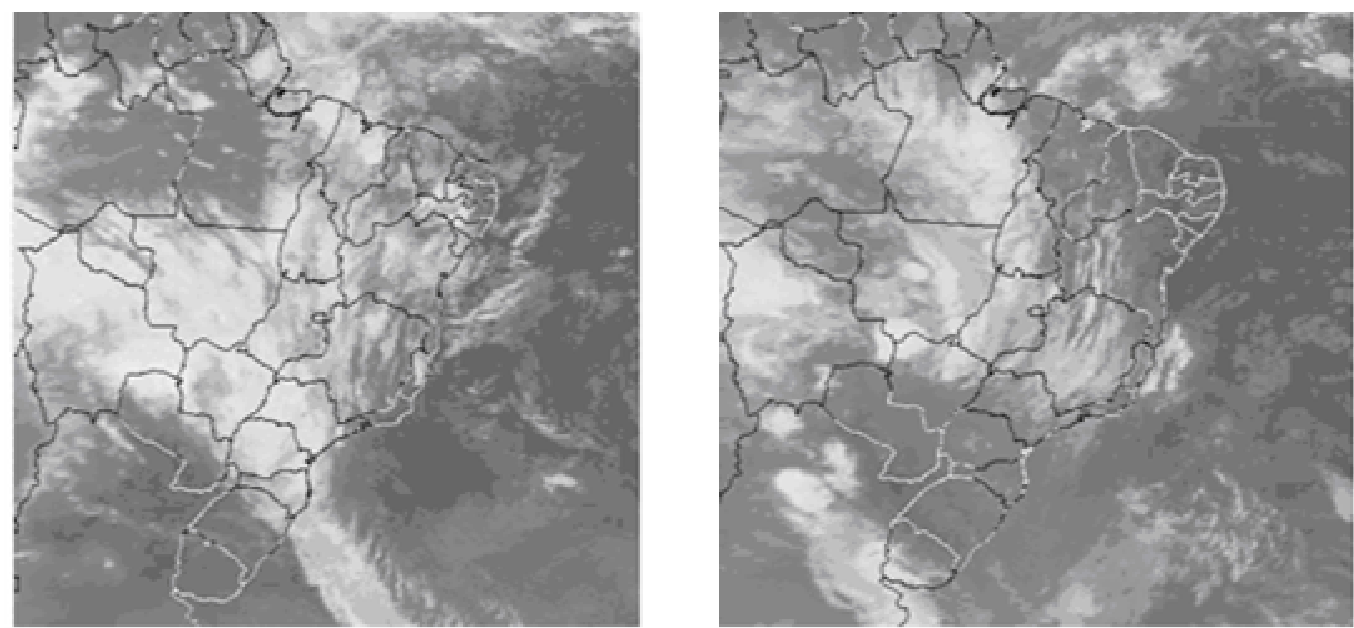

Figura 2. Imagens de satélites GOES, de uma ZCAS que se estendeu de 20/01 a 29/01/97.

Na Figura 3 pode-se observar que as séries de precipitações pluviais utilizadas estão, basicamente, sob o eixo Noroeste - Sudoeste, que é a estrutura da ZCAS, de maneira geral. Tendo por base as ZCAS classificadas entre 20 de janeiro e 29 de janeiro de 1997, foram analisadas as chuvas, dentro deste período, comparativamente ao mesmo período, para outros anos dentro do período estudado.

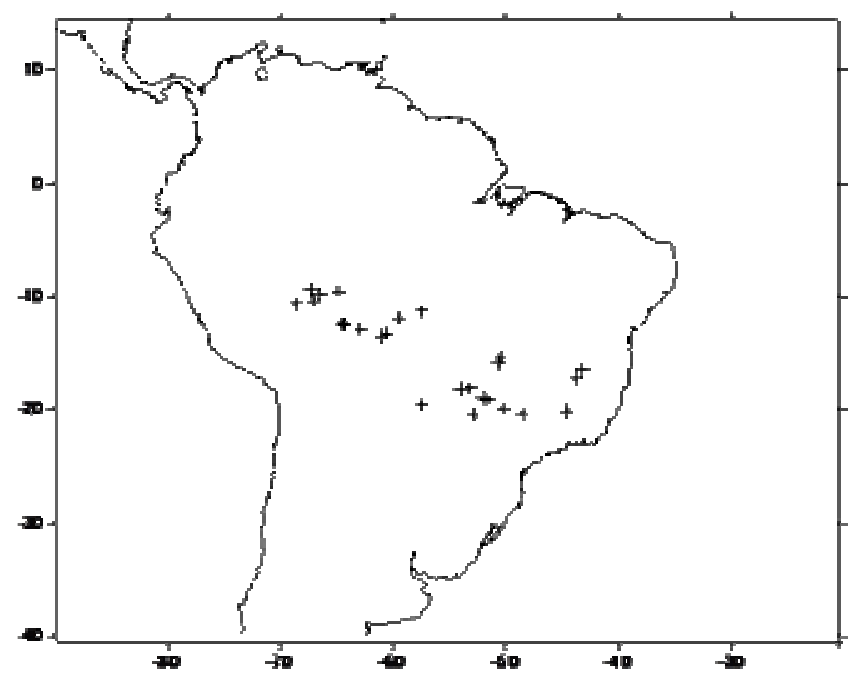

Figura 3. Estações selecionadas para análise da precipitação pluvial sob a região de ocorrência das ZCAS. 
Tabela 1. Total de precipitação pluvial para o período da ocorrência de ZCAS de 20/01 a 29/011997, comparativamente ao mesmo período e para outros anos; (****) sem informações.

\begin{tabular}{rrrrrrr}
\hline CÓDIGO & $\begin{array}{r}\text { TOTALPP } \\
\mathbf{1 9 7 5}\end{array}$ & $\begin{array}{r}\text { TOTALPP } \\
\mathbf{1 9 8 2}\end{array}$ & $\begin{array}{r}\text { TOTALPP } \\
\mathbf{1 9 8 3}\end{array}$ & $\begin{array}{r}\text { TOTALPP } \\
\mathbf{1 9 8 5}\end{array}$ & $\begin{array}{r}\text { TOTALPP } \\
\mathbf{1 9 9 7}\end{array}$ & \multicolumn{1}{c}{ TOTAL } \\
$\mathbf{2 0 0 0}$
\end{tabular}

Na Tabela 1 tem-se algumas análises do total de precipitação pluvial para o ano 1997 (ano de ocorrência de uma ZCAS intensa) e outros anos escolhidos aleatoriamente. Os asteriscos na Tabela I, representam a falta de informações no período. O ano 1997 apresentou significativa variabilidade da precipitação pluvial, no período de 20 a 29 de janeiro, sob o eixo da ZCAS. Outros anos, no entanto, também apresentaram chuvas intensas, ainda que não tenham sido analisadas ocorrências de Complexos Convectivos ou ZCAS, nos anos da Tabela 1.

As imagens de satélites da Figura 4 apresentam outro período de ocorrência de ZCAS. Nesse caso não foi feito nenhuma análise estatística, mas simplesmente apresentado a evolução do sistema ao longo do mês fevereiro de 2000. Tal apresentação tem a finalidade de mostrar outro padrão de ZCAS, no continente sul americano. Pode-se observar a intensa nebulosidade sobre a parte central do Brasil, além da região norte, influenciando as chuvas em grande parte do território brasileiro, assim como a região sul do Brasil.

\section{Outras escalas de abordagem}

Além da análise subjetiva das Zonas de Convergências do Atlântico Sul, também foram realizados diversas estatísticas básica para estudar as variabilidades da precipitação pluvial na área de estudo. Com base em um 
conjunto de dados, foi possível se traçar isolinhas de médias, desvios padrão e coeficiente de variação, além de calcular as anomalias para alguns anos escolhidos com base em anos mais secos ou mais úmidos, ou seja, anos influenciados por evento El Niño e La Niña, principalmente.
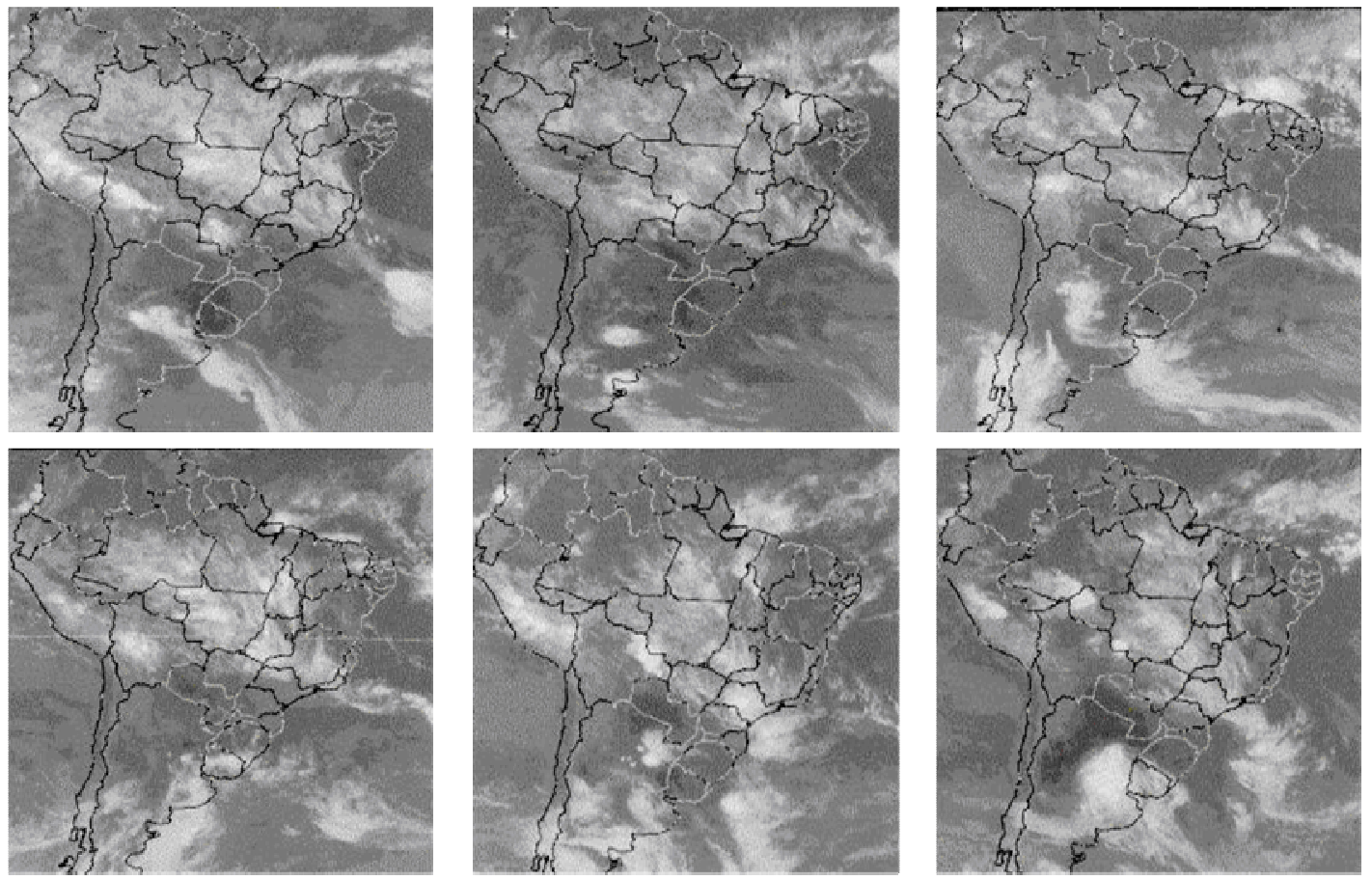

Figura 4. Imagens do satélite GOES-8 do dia 6 a 11 de fevereiro de 2000.

A análise da precipitação pluvial na região sul do Brasil com base em dados cedidos pela Agência Nacional de Água (ANA), período 1972 a 1997, é apresentada na Figura 5.

Na Figura 6 pode-se observar as isolinhas de altitudes para a região de estudo. As maiores altitudes chegaram a $1000 \mathrm{~m}$ na Serra do Mar (litoral) e Serra Geral (Guarapuava). Desta forma, tem-se baixas altitudes (ao nível do mar) e altitudes significativas que influenciam na geração de chuvas orográfica bem marcada em algumas regiões.

A análise da precipitação pluvial na região sul do Brasil com base em dados cedidos pela Agência Nacional de Água (ANA), período 1972 a 1997 (Figura 6).

$\mathrm{Na}$ Figura 7, foram classificadas áreas homogêneas, podendo-se observar, basicamente, quatro áreas. Esta classificação de quatro áreas foi realizada utilizando dados totais anuais com base nas 127 séries pluviométricas. Para tanto foi aplicado o método de análise multivariado, método de Ward e distância euclidiana.

Nas Figuras 8, 9 e 10 apresentam-se as isolinhas de precipitação pluvial, desvio padrão e coeficiente de variação, respectivamente, dentro do período de estudo. As isolinhas da média de precipitação pluvial apresentou 
valores de chuvas de $1900 \mathrm{~mm}$ no Estado do Paraná (a sudoeste), parte central de Santa Catarina e norte do Rio Grande do Sul (Figura 8). As dispersões (calculadas através do desvio padrão), além do coeficiente de variação apresentaram maior variabilidade também nessa região (Figuras 9 e 10).

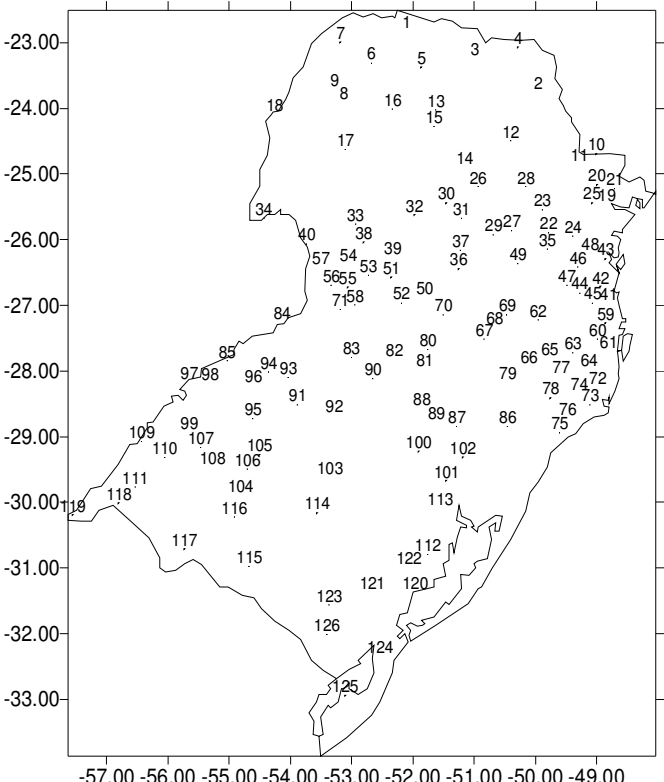

Figura 5. Base de dados utilizados para esse estudo.

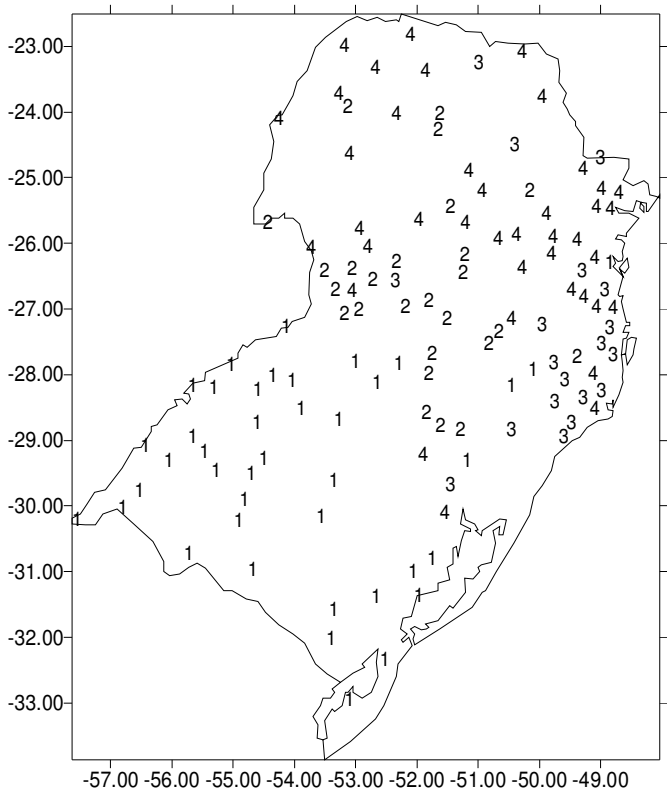

Figura 7. Base de dados utilizados para análise da área de estudo.

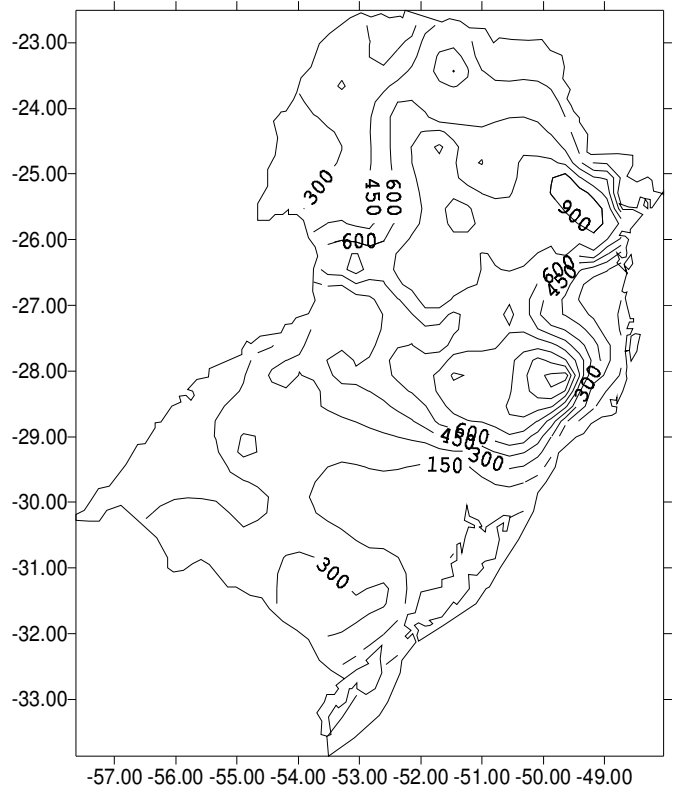

Figura 6. Distribuição das altitudes na área de estudo.

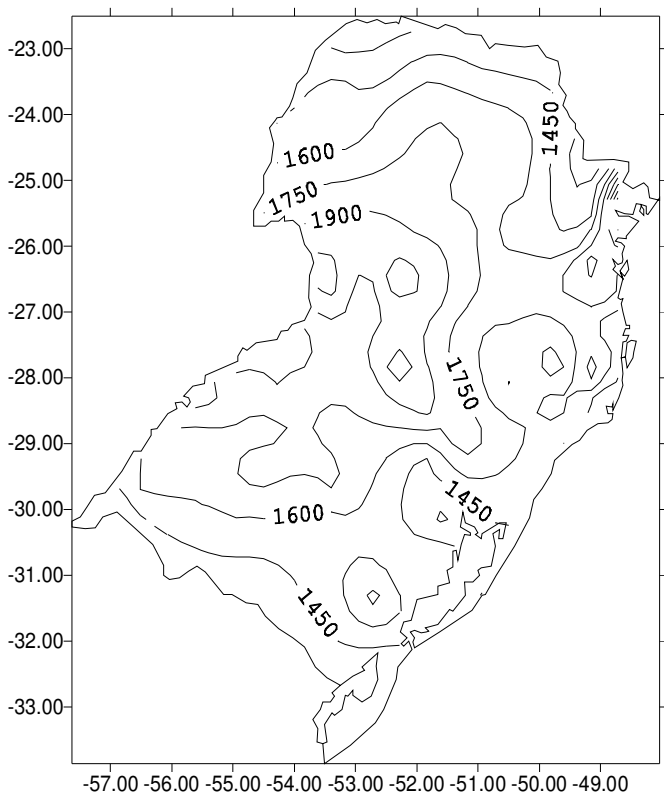

Figura 8. Média da precipitação anual (mm) para o Sul do Brasil (1972-1997). 


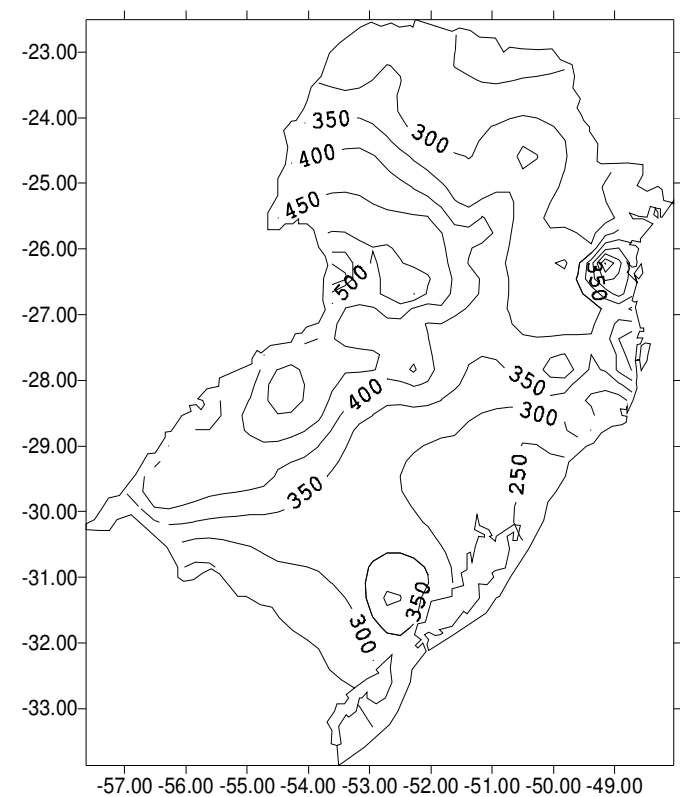

Figura 9. Desvio padrão da precipitação anual $(\mathrm{mm})$ para o Sul do Brasil (1972-1997).

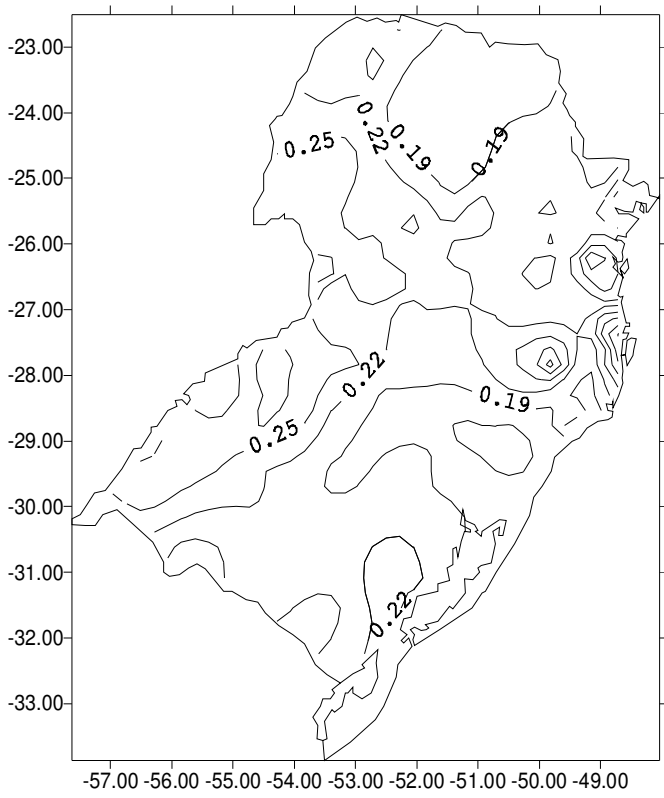

Figura 10. Coeficiente de variação da precipitação anual $(\mathrm{mm})$ para o Sul do Brasil (1972-1997).

Nas Figuras 11 a 20 são apresentados algumas anomalias, para alguns anos, dentro do período de estudo. As anomalias de 1977 foram essencialmente negativas no Paraná, a oeste de Santa Catarina e Rio Grande do Sul, Figura 10. Já a parte costeira da região Sul apresentou valores de $300 \mathrm{~mm}$ de precipitação pluvial acima da média, do período estudado.

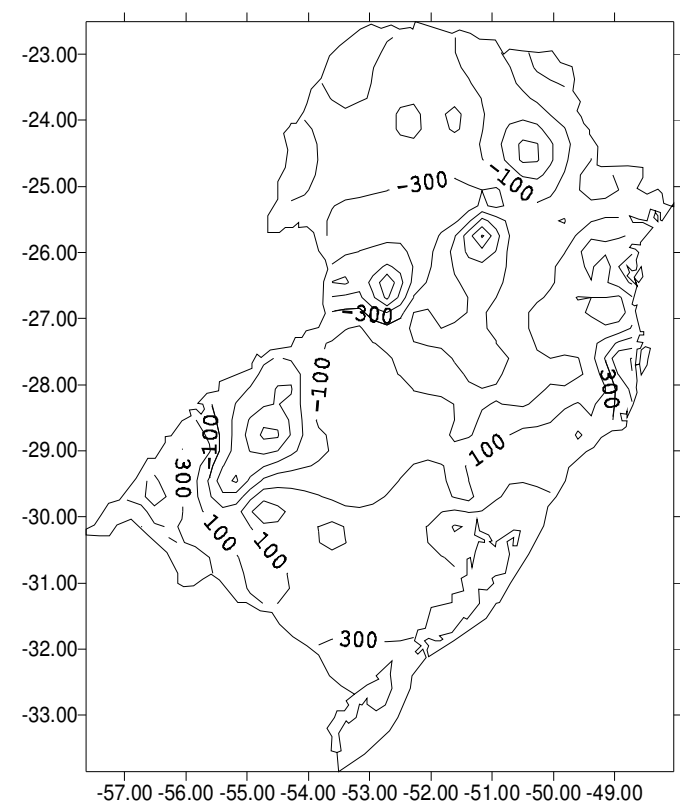

Figura 11. Anomalia da precipitação pluvial anual ( $\mathrm{mm}$ ) para 1977.

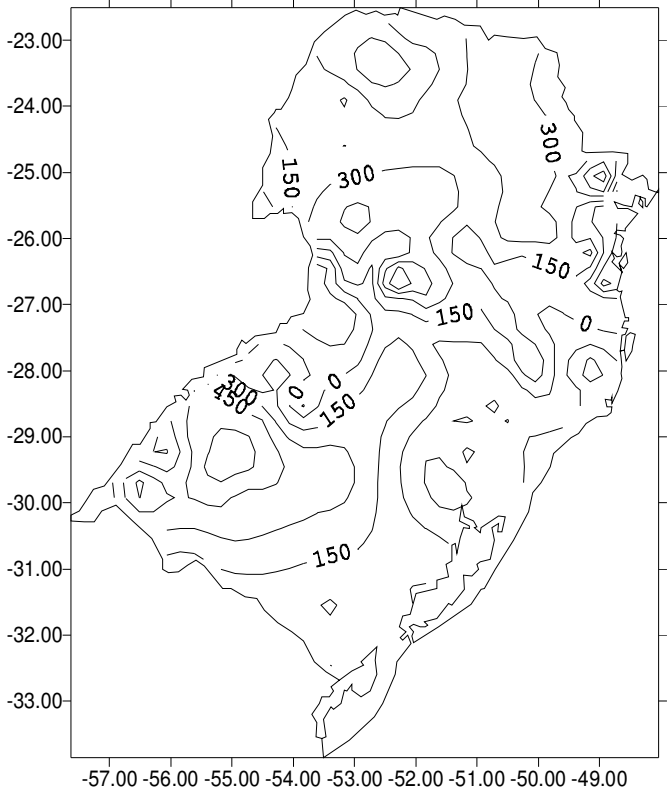

Figura 12. Anomalia da precipitação pluvial anual (mm) para 1982. 
Os anos 1982 e 1983 (Figuras 12 e 13) apresentaram significativa precipitação pluvial, com valores positivos de anomalia em toda a região. $\mathrm{Na}$ Figura 12 pode-se observar que os maiores valores da anomalia da precipitação pluvial ocorreram a sudoeste dos Estados do Paraná e Santa Catarina, com $300 \mathrm{~mm}$ de precipitação pluvial acima da média climatológica do período. O ano 1983, foi significativamente chuvoso, podendo-se através da Figura 13 observar chuvas acima da média, da ordem de $1200 \mathrm{~mm}$ à oeste de Santa Catarina, sendo os Estados de Santa Catarina e Paraná, mais chuvosos, no referido ano.

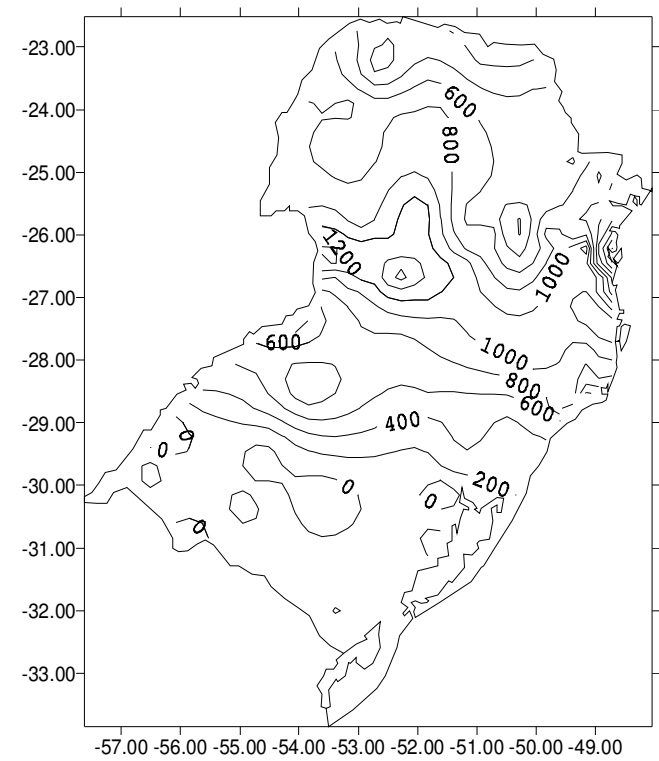

Figura 13. Anomalia da precipitação pluvial anual ( $\mathrm{mm})$ para 1983.

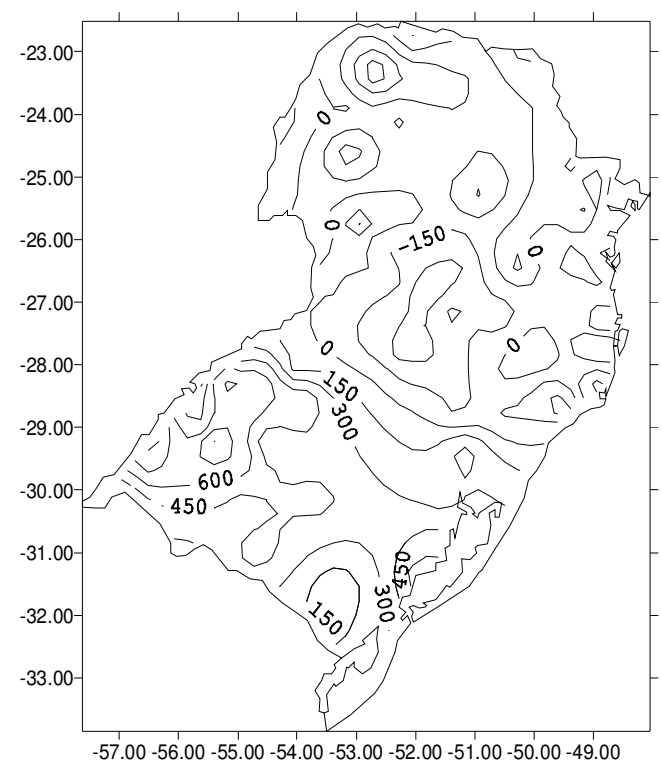

Figura 15. Anomalia da precipitação pluvial anual $(\mathrm{mm})$ para 1986.

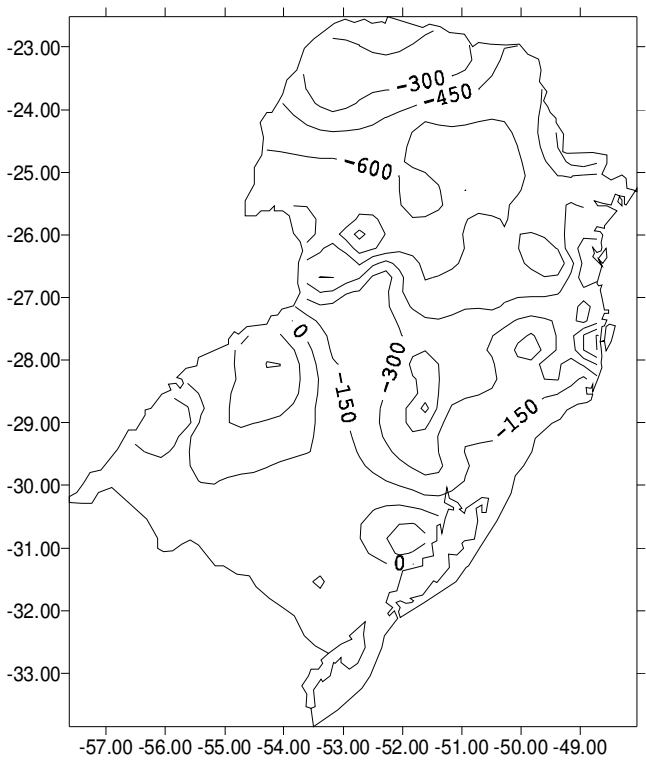

Figura 14. Anomalia da precipitação pluvial anual (mm) para 1985.

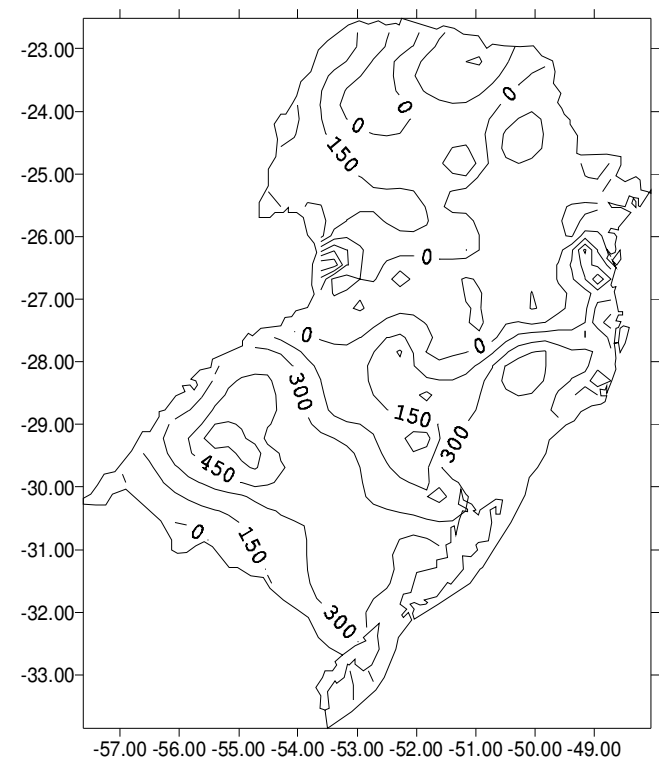

Figura 16. Anomalia da precipitação pluvial anual ( $\mathrm{mm}$ ) para 1987. 
Segundo Trenberth (1997) ocorreu um evento El Niño intenso entre junho de 1982 e dezembro de 1983, sendo de fácil detecção ao analisar as anomalias desses dois anos nas Figuras 12 e 13.

Também de acordo com a classificação de Trenberth, Tabela 2, o ano 1985 (Figura14) apresentou anomalias de precipitação pluvial negativa (abaixo da média climatológica do período analisado), com menores chuvas ao centro e oeste do Paraná, com $-600 \mathrm{~mm}$.

Outros dois anos analisados foram 1986 (Figura 15) e 1987 (Figura 16). Os dois anos apresentaram valores de anomalias positivas em, praticamente toda a região estudada. Nota-se, no entanto, que algumas áreas da região de estudo as chuvas foram normais, ou seja, dentro dos valores médios climatológicos.

Tabela 2. Eventos El Niño e La Niña desde 1970 até 2002, definidos a partir da temperatura da superfície do mar no Oceano Pacífico para a região do El Niño $(1+2)$ e excedendo valores de $0,4^{\circ} \mathrm{C}$ (positivo ou negativo).

\begin{tabular}{cccc}
\hline Período de EI Niño & Duração (meses) & Período de La Niña & Duração (meses) \\
\hline Jan/72 a fev/73 & 14 & Mar/70 a dez/71 & 22 \\
Mai/76 a jan/77 & 9 & Abr/73 a fev/74 & 11 \\
Jun/79 a jan/80 & 8 & Out/74 a jan/76 & 16 \\
Jul/82 a dez/83 & 18 & Jan/85 a dez/85 & 12 \\
Out/86 a dez/87 & 15 & Abr/88 a dez/88 & 9 \\
Nov/91 a jun/92 & 8 & Mai/89 a set/89 & 5 \\
Fev/93 a jun/93 & 5 & Mar/94 a set/94 & 7 \\
Out/94 a fev/95 & 5 & Abr/95 a ago/95 & 5 \\
Mar/97 e out/98 & 20 & Abr/96 a jan/97 & 10 \\
& & Abr/99 a jan/2000 & 10 \\
& & Jun/2000 a jan/01 & 8 \\
\end{tabular}

Fonte: Trenberth (1997), adaptada por Baldo (2001) e atualizada.

Em 1988 e 1989 (Figuras 17 e 18), ocorreu uma La Niña forte, sendo, portanto, esperada a anomalia negativa em toda a área de estudo, principalmente no ano 1988.

Nas Figuras 19 e 20, são apresentados anomalias dos anos 1991 e 1997. Em 1991 as anomalias negativas são observadas em toda região, sendo os menores valores $(-600 \mathrm{~mm})$ na parte central da referida região. Em 1997 as anomalias forma positivas em toda região com valores de $150 \mathrm{~mm}$ a $600 \mathrm{~mm}$, acima da média climatológica.

Pode-se concluir dessa análise de anomalias, significativa variabilidade de ano para ano e a influência dos eventos ENOS (El Niño e La Niña) sobre a área de estudo. 


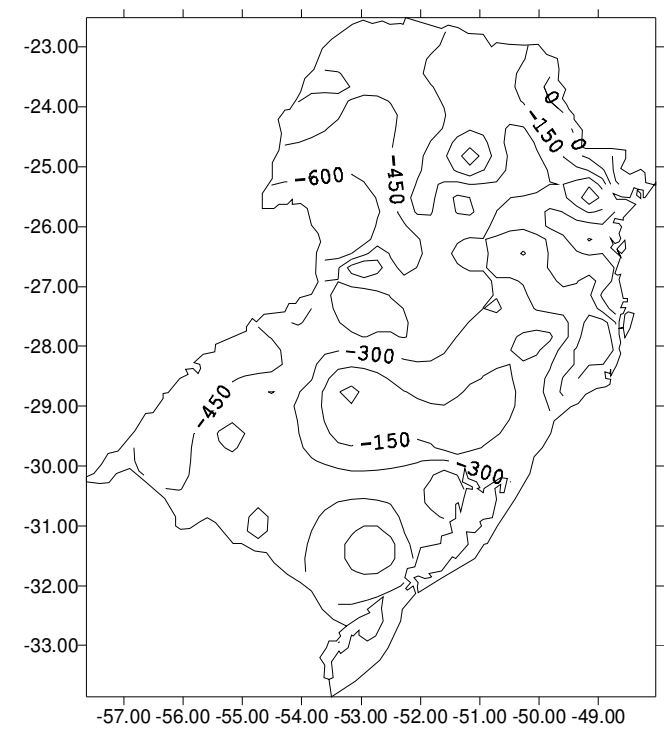

Figura 17. Anomalia da precipitação pluvial anual $(\mathrm{mm})$ para 1988.

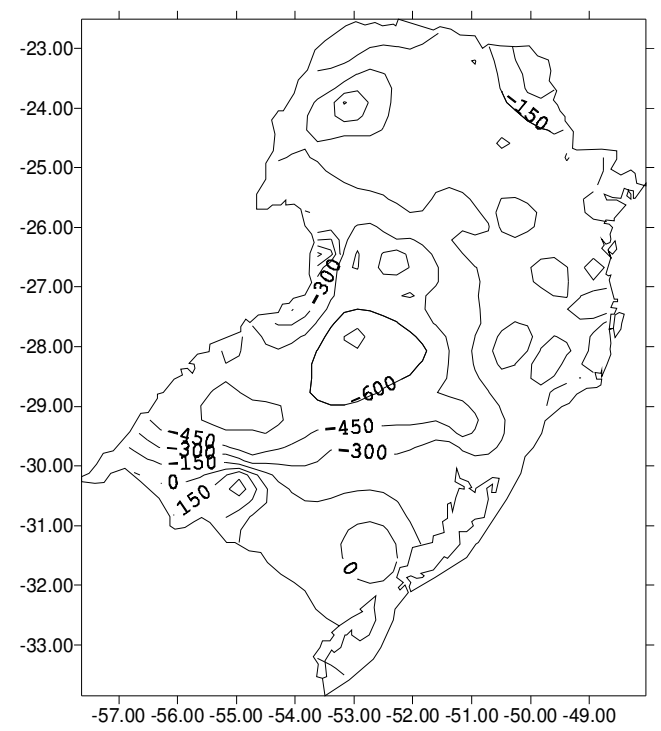

Figura 19. Anomalia da precipitação pluvial anual ( $\mathrm{mm}$ ) para 1991 (El Niño).

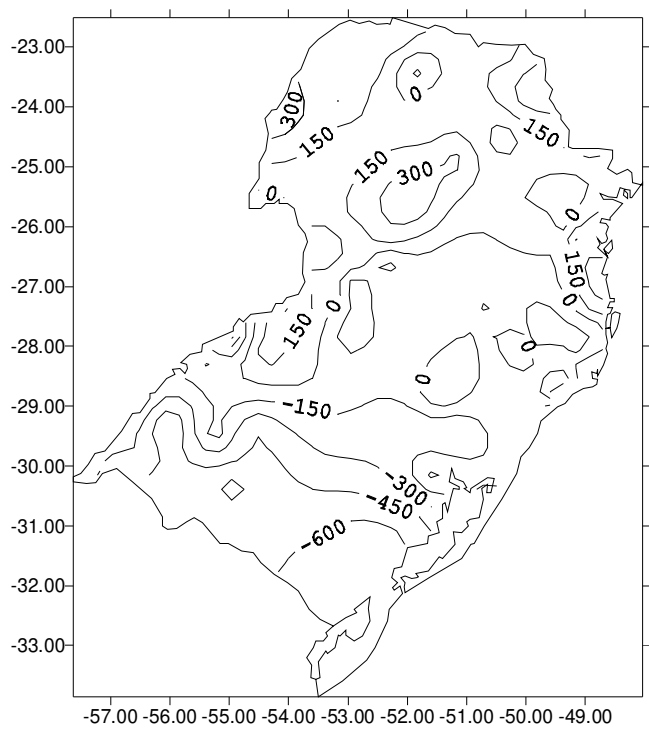

Figura 18. Anomalia da precipitação pluvial anual (mm) para 1989.

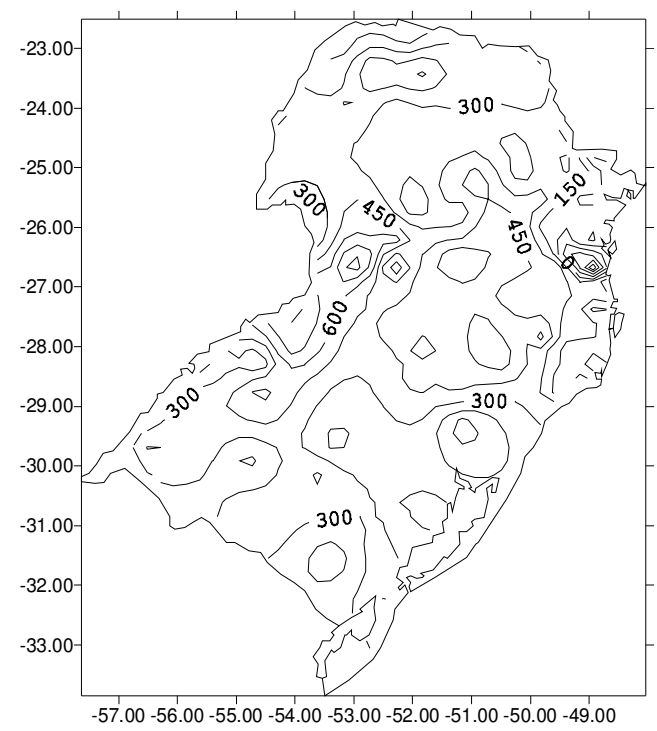

Figura 20. Anomalia da precipitação pluvial anual (mm) para 1997 (El Niño forte).

\section{Conclusão}

A variabilidade da precipitação pluvial na região sul é significativamente complexa, com atuações de diversas dinâmicas importantes, como massas polares, sistemas convectivos, massas polares, maritimidade e continentalidade, basicamente.

Os eventos El Niño e La Niña não determinam a chuvas na região sul, mas são importantes, quanto à intensidade das mesmas na área analisada, sendo alguns episódios mais intensos que outros. 


\section{ReferênciasBibliográficas}

ALGARVE, V. R.; CAVALCANTI, I. F.A., 1994. Características da circulação atmosférica associadas à ocorrência de geadas no sul do Brasil. Congresso Brasileiro de Meteorologia, 8:545-547. Belo Horizonte, MG. Anais II.

CASARIN, D. P. e V. E. KOUSKY, 1986: Anomalias de precipitação no sul do Brasil e variações da circulação atmosférica. Rev. Bras. Meteo., 1, 83-90.

FIGUEROA, S. N., P. SATYAMURTY e P. L. SILVA DIAS, 1994: Simulations of the summer circulation over the South American region with an ETA coordinate model. J. Atmos. Sci., 52, 1573-1584.

GANDU, A. W. e J. E. GEISLER, 1991: A primitive equations model study of the effect of topography on the summer circulation over tropical South America. J. Atmos. Sci., 48, 1822-1836.

GRIMM, A. M., 1992. Influência remota de fontes tropicais anômalas de calor. Tese de Doutoramento. Instituto Astronômico e Geofísico, USP. São Paulo, 216p.

HURREL, J. W., VINCENT, D. G., 1991: On the maintenance of short-term subtropical westerly maxima in the Southern Hemisphere during SOP-1, FGGE. J. Climate, 4, 1009-1022.

KALNAY, E., K. C. MO e J. PAEGLE, 1986: Large-amplitude, short-scale stationary Rossby waves in the Southern Hemisphere: Observations and mechanistic experiments to determine their origin. J. Atmos. Sci., 43, 252-275.

KODAMA, Y-M., 1992: Large-scale common features of sub-tropical precipitation zones (the Baiu Frontal Zone, the SPCZ, and the SACZ). Part I: characteristics of subtropical frontal zones. J. Meteor. Soc. Japan, 70, 813-835.

KODAMA, Y-M., 1993: Large-scale common features of sub-tropical precipitation zones (the Baiu Frontal Zone, the SPCZ, and the SACZ). Part II: Conditions of the circulations for generating the STCZs. J. Meteor. Soc. Japan, 71, 581-610.

KOUSKY, V. E.; CAVALCANTI, I. F., 1984. Eventos El Niño - Oscilação Sul: características, evolução e anomalias de precipitação. Ciências e Cultura, 36 (11), 1188-99.

KOUSKY, V. E.; ROPELEWSKI, C. H., 1989. Extremes in the Southern Oscillation and their relationship to precipitation anomalies with empahisis on the South América region. Revista Brasileira de Meteorología, 4, 351-363.

QUADRO, M. F. L., 1994: Estudo de episódios de zonas de convergência do Atlântico Sul (ZCAS) sobre a América do Sul. Dissertação de Mestrado, INPE, São José dos Campos (SP), $97 \mathrm{pp}$.

RAO, V. B., HADA, K., 1990. Characteristic of Rainfall over Brazil: Annual variations and connections with the Southern Oscillations. Theor. Appl. Climatol., 42, 81-91.

ROPELEWSKI, M. A.; HALPERT, S., 1987. Global and regional scale precipitation patterns associated with the El Niño/Southern Oscillation. Mon. Weather Rev., 115, 16061626. 